\title{
Erratum to: Telling our stories: heroin- assisted treatment and SNAP activism in the Downtown Eastside of Vancouver
}

Susan Boyd ${ }^{1}$, Dave Murray ${ }^{2}$, SNAP $^{3}$ and Donald MacPherson ${ }^{3 *}$

\section{Erratum}

"Upon publication of the original article [1], it was noticed that there was an error in the last sentence of the first paragraph. The sentence should read: Prior to and following their dose, NAOMI staff observes each participant for adverse effects."

\footnotetext{
Author details

${ }^{1}$ Faculty of Human and Social Development, University of Victoria, Victoria, BC V8W 2Y2, Canada. ${ }^{2}$ /o VANDU, 380 East Hastings Street, Vancouver, BC V6A 1P4, Canada. ${ }^{3}$ Canadian Drug Policy Coalition, Centre for Applied Research in Mental Health and Addictions, Simon Fraser University, \#2400 -515 West Hastings Street, Vancouver, BC V6B 5K3, Canada.
}

Received: 24 May 2017 Accepted: 24 May 2017

Published online: 09 June 2017

\section{Reference}

1. Telling our stories: heroin-assisted treatment and SNAP activism in the Downtown Eastside of Vancouver. Harm Reduct J. 2017 14:27. DOI 10.1186/ s12954-017-0152-3

\footnotetext{
* Correspondence: Donald_macpherson@sfu.ca

${ }^{3}$ Canadian Drug Policy Coalition, Centre for Applied Research in Mental

Health and Addictions, Simon Fraser University, \#2400 -515 West Hastings

Street, Vancouver, BC V6B 5K3, Canada
} 